\title{
Penerapan SOP Bagi Mahasiswa PKL Pada Departemen Food And Beverage Service The Oberoi Beach Resort, Bali
}

\author{
Ida Ayu Putu Padma Sri Wahyuni, I Putu Gede Parma \\ Undiksha
}

\begin{abstract}
Abstrak
Penelitian ini bertujuan untuk (1). Mengetahui proses penyampaian SOP bagi mahasiswa magang pada departemen Food and Beverage Service (2). Cara penerapan SOP bagi mahasiswa magang pada departemen Food and Beverage Service. Penelitian ini termasuk jenis penelitian deskriptif kualitatif, dengan metode wawancara dan dokumentasi dalam pengumpulan data. Subjek dalam penelitian ini adalah staff HRD dan senior pada room service section di The Oberoi Beach Resort, Bali. Hasil penelitian menunjukkan bahwa (1). Proses penyampaian SOP bagi mahasiswa magang dilakukan dengan cara pembekalan materi pada saat pra training, role play training dan penyampaian SOP 15 menit sebelum memulai shift. (2). Cara peneraparan SOP yang dilakukan adalah briefing dan pelatihan-pelatihan kepada mahasiswa magang. Dari hasil penelitian ini dapat dilakukan penelitian lanjutan mengenai pentingnya pemahaman SOP bagi para mahasiswa magang dalam ruang lingkup departemen Food and Beverage Service yang lebih luas.
\end{abstract}

Kata kunci: SOP, Mahasiswa Magang, Food and Beverage Service

This study aims to explore (1). The SOP delivery process for intern students in the Food and Beverage Service department (2). The implementation of SOPs by intern students in the Food and Beverage Service Department. This research was a qualitative descriptive research, with interview method and documentation in data collection. The subjects in this study were HRD staff and seniors in the room service section at The Oberoi Beach Resort, Bali. The results showed that (1). The process of delivering SOP for internship students was done by providing material during pre training, role play training and delivering SOP 15 minutes prior to new shift. (2). The SOP was delivered in the form of briefing and training for trainees. From the results of this study it may be necessary to further research on the importance of understanding SOP for intern students in a broader scope.

Keywords: Food and Beverage Service, Internship Students, SOP

\section{Pendahululuan}

Industri pariwisata merupakan salah satu industri yang memiliki tingkat pertumbuhan yang signifikan dari tahun ke tahun. Industri perhotelan tidak dapat dipisahkan dari dunia pariwisata. Tanpa adanya kegiatan pariwisata, dunia perhotelan tidak akan berjalan dan berkembang dengan pesat. Begitu pula sebaliknya, pariwisata tidak akan berjalan jika tidak ada hotel yang menjadi salah satu fasilitas penunjang dari dunia pariwisata. Maka dari itu, dunia pariwisata memiliki hubungan yang sangat erat dengan industri perhotelan dan dapat dikatakan bahwa industri perhotelan merupakan salah satu pondasi pendukung dari dunia pariwisata.

Perhotelan merupakan salah satu industri yang berkembang sangat pesat. 
JMPP, Vol 3 No 1, April 2020

p-ISSN: 2654-9719

Perkembangan perhotelan ini dipengaruhi oleh pesatnya perkembangan wisata di suatu daerah. Hal ini sejalan dengan pembangunan hotel yang terjadi secara terus menerus. Seiring dengan perkembangan jaman, fungsi dari hotel bukan hanya sekedar tempat menginap dan penyedia makanan dan minuman melainkan juga sebagai fasilitas untuk hiburan, olahraga bahkan sebagai tempat penyedia jasa terapi. Hotel merupakan fasilitas yang dapat digunakan para wisatawan selama 24 jam.

Untuk meningkatkan pelayanan pihak industri perhotelan memerlukan banyak karyawan yang terampil dalam bidang perhotelan yang dapat bekerja dan melayani wisatawan berdasarkan SOP (Standard Operational Procedures) serta memiliki kemampuan dalam berbahasa asing. Bukan hanya untuk para karyawan, SOP (Standard Operational Procedures) juga berlaku untuk para mahasiswa jurusan perhotelan yang melakukan kegiatan magang di suatu hotel agar kegiatan operasional kerja berjalan dengan baik dan lancar. Maka dari itu, SOP (Standard Operational Procedures) dapat dikatakan sebagai acuan untuk menjalankan operasional dalam memberikan pelayanan guna mengembangkan suatu hotel. SOP (Standard Operational Procedures) merupakan acuan baku dalam kegiatan operasional hotel. Dikatakan demikian, karena SOP (Standard Operational Procedures) adalah pedoman untuk semua karyawan dalam menjalankan prosedur pelayanan terhadap tamu. Pada dasarnya setiap masing-masing departemen memiliki SOP (Standard Operational Procedures) yang berbeda antara satu departemen dengan departemen yang lainnya. Sehingga dengan adanya prosedur ini diharapkan semua karyawan dan mahasiwa magang dapat memahami isi dari prosedur tersebut.

Food and Beverages Service (FBS) atau Tata Hidang adalah salah satu departemen hotel yang memiliki SOP (Standard Operational Procedures) tentang pelayanan terhadap tamu. Di suatu bagian hotel, departemen yang memiliki tanggung jawab atas pelayanan makanan dan minuman disebut dengan Tata Hidang yang merupakan salah satu departemen yang memiliki tugas untuk menyajikan makanan dan minuman. Bentuk dari penyajian makanan dan minuman dapat mempengaruhi berkembangnya suatu hotel, dilihat dari presentasi makanan dan minuman yang disajikan. Peningkatan pelayanan pada Tata Hidang berguna untuk mendapatkan guest comment yang dapat membangun motivasi kerja para karyawan dan mahasiswa magang. Dengan adanya SOP (Standard Operational Procedures) pada departemen Tata Hidang diharapkan para karyawan dan mahasiswa magang dapat menjalankan kegiatan operasional secara terstruktrur dan dapat memberikan pelayanan yang memuaskan kepada para tamu. Penelitian ini bertujuan untuk cara penerapan SOP bagi mahasiswa PKL guna meningkatkan pelayanan di departemen Food and Beverage Service.

Berdasarkan latar belakang penelitian yang telah dipaparkan, maka penelitian ini bertujuan untuk mengetahui proses penyampian dan cara penerapan SOP bagi 
JMPP, Vol 3 No 1, April 2020

p-ISSN: 2654-9719

mahasiswa PKL pada departemen Food and Beverage Service.

\section{KajianPustaka}

\subsection{Pengertian Food and Beverage Service}

Pengertian Food and Beverage menurut Soekresno dan Pendit (1998:4) adalah sebuah bidang usaha yang merupakan bagian usaha seperti hotel yang bertanggung jawab terhadap kebutuhan, karena dalam pelayanannya meyediakan makanan dan minuman serta dalam kebutuhan lain yang terkait dari sebuah hotel atau dikelola secara komersial. Dalam Bahasa Indonesia Food and Beverage Service disebut dengan Tata Hidang. Pengertian Tata Hidang menurut Mertayasa (2012:2) adalah bagian yang mempunyai tugas pokok untuk menyiapkan dan menyajikan makanan dan minuman kepada para tamu baik di hotel maupun di luar hotel.

\subsection{Fungsi dan Tujuan Food and Beverage Service}

Beberapa fungsi dari Food and Beverage Service adalah melayani pelayanan makanan dan minuman yang dapat dilakukan di restoran, bar, banquet dan room service, mendatangkan dan meningkatkan keuntungan bagi pihak manajemen, memelihara kebersihan dan keutuhan peralatan di food and beverage service, yang dilakukan oleh seksi Steward dan memberikan pelayanan dan menjaga hubungan baik dan harmonis kepada semua tamu. Sedangkan tujuan dari Food and Beverage Service menurut Soekarno dan Pendit (1998:5) adalah menjual makanan dan minuman sebanyakbanyaknya dengan harga yang sesuai, memberikan pelayanan sebaik-baiknya kepada tamu sehingga tamu merasa puas hal ini menyangkut mutu pelayanan, mutu makanan dan minuman, sikap karyawan, dekorasi ruangan serta suasana sekitar, peralatan yang dipakai dan sanitasinya dan mendapatkan keuntungan sebesar-besarnya dan untuk kesinambungan usaha.

\subsection{Pengertian SOP}

Menurut Moekijat (2008), SOP (Standard Operational Procedures) adalah urutan langkah-langkah (atau pelaksanaan-pelaksanaan pekerjaan), di mana pekerjaan tersebut dilakukan, bagaimana melakukannya, bilamana melakukannya, dan siapa yang melakukannya. Menurut Tjipto Atmoko (2011), SOP merupakan pedoman atau acuan untuk melakukan tugas pekerjaan sesuai dengan fungsi dan alat penilaian kinerja instansi pemerintah berdasarkan indikator-indikator teknis, administrative dan procedural sesuai tata kerja, prosedur kerja dan sistem kerja pada unit kerja yang bersangkutan. Berdasarkan beberapa pengertian SOP menurut para ahli dapat disimpulkan bahwa SOP 
JMPP, Vol 3 No 1, April 2020

p-ISSN: 2654-9719

merupakan suatu acuan yang digunakan untuk melakukan tugas pekerjaan yang berisikan langkah-langkah pelaksanaan pekerjaan, di mana pekerjaan tersebut dilakukan, bagaimana melakukannya, bilamana melakukannya, dan siapa yang melakukannya.

\subsection{Fungsi dan Tujuan SOP}

Fungsi dari SOP sebagai berikut (Indah Puji, 2014:35) yaitu, memperlancar tugas petugas/pegawai atau tim/unit kerja, sebagai dasar hukum bila terjadi penyimpangan, mengetahui dengan jelas hambatan-hambatannya dan mudah dilacak, mengarahkan petugas/pegawai disiplin dalam bekerja dan sebagai pedoman dalam melaksanakan pekerjaan rutin. Sedangkan tujuan SOP adalah sebagai berikut (Indah Puji, 2014:30) yaitu, untuk menjaga konsistensi tingkat penampilan kinerja atau kondisi tertentu dan kemana petugas dan lingkungan dalam melaksanakan sesuatu tugas atau pekerjaan tertentu, sebagai acuan dalam pelaksanaan kegiatan tertentu bagi sesame pekerja, dan supervisor, untuk menghindari kegagalan atau kesalahan (dengan demikian menghindari dan mengurangi konflik), keraguan, duplikasi serta pemborosan dalam proses pelaksaan kegiatan, merupakan parameter untuk menilai mutu pelayanan, untuk lebih menjamin penggunaan tenaga dan sumber daya secara efisien dan efektif, untuk menjelaskan alur tugas, wewenang dan tanggung jawab dari petugas yang terkait, sebagai dokumen yang akan menjelaskan dan menilai pelaksaan proses kerja bila telah terjadi suatu kesalahan atau dugaan mal praktek dan kesalahan administratif lainnya, sehingga seifatnya melindungi rumah sakit dan petugas, sebagai dokumen yang digunakan untuk pelatihan dan sebagai dokumen sejarah bila telah dibuat revisi SOP yang baru.

\subsection{Manfaat dan Prinsip SOP}

Manfaat dari SOP bagi suatu organisasi sebagai berikut (Permenpan No.PER/21/M-PAN/11/2008) yaitu sebagai standarisasi cara yang dilakukan pegawai dalam menyelesaikan pekerjaan khusus, mengurangi kesalahan dan kelalaian, SOP membantu staff menjadi lebih mandiri dan tidak tergantung [ada intervensi manajemen, sehingga akan mengurangi keterlibatan pimpinan dalam pelaksaan proses sehari-hari, meningkatkan akuntabilitas dengan mendokumentasikan tanggung jawab khusus dalam melaksanakan tugas, menciptakan ukuran standar kinerja yang akan memberikan pegawai cara konkret untuk memperbaiki kinerja serta membantu mengevaluasi usaha yang telah dilakukan, menciptakan bahan-bahan training yang dapat membantu pegawai baru untuk cepat melakukan tugasnya. menunjukkan kinerja bahwa organinasi efisien dan dikelola dengan baik, menyediakan pedoman bagi setiap pegawai di unit pelayanan dalam melaksanakan pemberian pelayanan sehari-hari, menghindari tumpang tindih pelaksaan 
JMPP, Vol 3 No 1, April 2020

p-ISSN: 2654-9719

tugas pemberi pelayanan, membantu penelusuran terhadap kesalahan-kesalahan prosedural dalam memberikan pelayanan dan menjamin proses pelayanan tetap berjalan dalam berbagai situasi.

Sedangkan prinsip dari SOP menurut Permenpan No.PER/21/M-PAN/11/2008 yaitu, Konsisten. SOP harus dilaksanakan secara konsisten dari waktu ke waktu, oleh siapapun, dan dalam kondisi apapu oleh seluruh jajaean organisasi pemerintah. Komitmen. SOP harus dilaksanakan dengan komitmen penuh dari seluruh jajaran organisasi, dari level yang paling rendah dan tertinggi. Perbaikan berkelanjutan. Pelaksaaan SOP harus terbuka terhadap penyempurnaan-penyempurnaan untuk memperoleh prosedur yang benar-benar efisien dan efektif. Mengikat. SOP harus mengikat pelaksanaan dalam melaksanakan tugasnya sesuai dengan prosedur standar yang telah ditetapkan. Seluruh unsur memiliki peran penting. Seluruh pegawai peran-peran tertentu dalam setiap prosedur yang distandarkan. Jika pegawai tertentu tidak melaksanakan perannya dengan baik, maka akan menganggu keselurahan proses, yang akhirnya juga berdampak pada proses penyelenggaraan pemerintah.Terdokumentasi dengan baik. Seluruh prosedur yang telah distandarkan harus didokumentasikan dengan baik, sehingga dapat selalu dijadikan referensi bagi setiap mereka yang memerlukan.

\section{Metodologi Penelitian}

Dalam artikel ini, jenis penelitian yang digunakan termasuk jenis penelitian deskriptif kualitatif yaitu metode yang berupa pencarian data melalui wawancara maupun pengamatan-pengamatan langsung kelapangan dan memaparkan hasil pengamatan kedalam bentuk pembahasan Penelitian ini dilakukan dengan metode wawancara dan dokumentasi dalam pengumpulan datanya. Jenis data yang digunakan dalam penelitian ini adalah menggunakan data kualitatif dengan menggunakan kata-kata untuk menggambarkan fakta dan fenomena yang diamati. Subjek penelitian ini adalah staff HRD dan staff di outlet room service di The Oberoi beach Resort, Bali..

\section{Hasil dan Pembahasan}

Sebuah kendala dapat menyebabkan suatu pekerjaan tidak selesai dan hasil yang diperoleh tidak sesuai dengan hasil yang diharapkan. SOP merupakan suatu dasar atau tolak ukur berhasil atau tidaknya suatu kegiatan operasional. Dengan adanya SOP semua staff melakukan pekerjaan dengan menggunakan acuan yang sama. Kendala yang sering dialami oleh beberapa mahasiswa magang yaitu memahami dan mengaplikasikan SOP yang sudah ditetapkan oleh pihak hotel. Ada beberapa faktor yang memengaruhi hal ini terjadi yaitu, banyak dari mahasiswa magang sudah melakukan kegiatan PKL sebelumnya di hotel yang berbeda namun mereka masih menjalankan kegiatan operasional dengan 
JMPP, Vol 3 No 1, April 2020

p-ISSN: 2654-9719

berpedoman pada SOP yang ditetapkan oleh hotel sebelumnya tempat mereka melakukan PKL, para mahasiswa magang susah untuk memahami isi dari SOP yang ditetapkan oleh pihak hotel dan para mahasiswa magang masih banyak yang belum bisa bekerja sama dengan beberapa senior dan adanya miss communication saat menjalankan kegiatan operasional.

Berdasarkan hasil penelitian, selain kemampuan kerja, kualitas pelayanan dan pengetahuan, SOP merupakan suatu acuan atau tolak ukur yang menjadi pedoman berhasil atau tidaknya suatu pekerjaan. SOP merupakan landasan untuk seluruh karyawan agar memberikan suatu pelayanan yang sama kepada para tamu. SOP dijalankan agar seluruh kegiatan operasional berjalan secara terstruktur dan menghindari adanya complaint dari tamu. SOP ini pun dibuat dengan beberapa tujuan yaitu, agar seluruh karyawan bertindak sesuai dengan standar yang sudah ditetapkan dan sesuai dengan job desc yang diberikan, menghindari adanya kecelakaan kerja, sebagai penjaga alur dan koridor masing-masing oleh seluruh karyawan dan dapat menjaga kualitas pelayanan serta membuat para karyawan bekerja secara konsisten.

Dari sisi manajemen, SOP digunakan untuk melakukan control serta pengawasan saat menjalankan kegiatan operasional secara menyeluruh. Beberapa cara penyampaian materi SOP dilakukan agar mempermudah seluruh karyawan memahami isi dari materi SOP tersebut. Penyampaian SOP pun diberikan kepada seluruh mahasiswa magang yang bertujuan untuk dapat membantu menjalankan seluruh kegiatan operasional dengan lancar. Salah satu cara yang dilakukan untuk menyampaikan materi SOP, yaitu pada saat masa pra training para mahasiswa magang akan diberikan materi SOP yang akan dibagikan sesuai dengan outlet dan job desc yang didapat melalui bentuk informasi yang tertulis. Beberapa cara yang dilakukan untuk menerapkan SOP pada saat kegiatan operasional yaitu memberikan briefing selama 15 menit sebelum dan sesudah menjalankan kegiatan opeasional dan para senior selalu mengingatkan para mahasiswa magang untuk memahami isi materi SOP yang sesuai dengan job desc yang diberikan. Langkah pertama dengan pemberian materi SOP, baik pengetahuan tentang Hotel, prosedur khusus di department maupun product knowledge. Setelah dirasa paham tentang hal tersebut diatas, dilanjutkan dengan proses pengamatan dilapangan, dimana trainee mengamati seniornya ketika melakukan standard SOP. Langkah selanjutnya trainee diberikan kesempatan untuk praktek dilapangan tanpa berinteraksi dengan tamu terlebih dahulu, dengan masih tetap dimonitoring dan dievaluasi oleh seniornya. Jika dianggap telah mampu melewati seluruh tahap diatas baru diberikan kesempatan untuk mengimplementasikan.

Perkembangan dan penerapan SOP meminimalisir perbedaan dan meningkatkan kualitas melalui implementasi konsisten dari sebuah proses atau prosedur di dalam 
JMPP, Vol 3 No 1, April 2020

p-ISSN: 2654-9719

organisasi, meskipun ada perubahan staff secara sementara ataupun tetap. SOP dapat mengindikasikan pemenuhan akan kebutuhan perusahaan dan pemerintah, serta dapat digunakan sebagai bagian dalam program pelatihan, karena SOP memuat instruksi kerja yang terperinci. Hal ini meminimalkan peluang terjadinya miskomunikasi dan meningkatkan keselamatan. SOP juga sering digunakan sebagai checklist oleh pengawas ketika ada prosedur audit. Dan yang terutama, keuntungan dari SOP yang benar adalah mengurangi tenaga kerja sekaligus dengan perbandingan, kredibilitas dan keamanan hukum yang meningkat (US Environmental Protection Agency, 2007). Oleh karena itu cara penyampaian materi SOP sangat mempengaruhi cara pemahaman SOP para mahasiswa magang serta bertujuan untuk memperlancar suatu kegiatan operasional dan menghindari adanya kecelakaan kerja.

\section{Penutup}

\subsection{Simpulan}

Berdasarkan penelitian yang dilakukan melalui wawancara, observasi langsung dan serta pembahasan yang sudah diuraikan pada bab sebelumnya, maka penulis dapat menarik beberapa kesimpulan yang berhubungan dengan judul yang penulis angkat yaitu pentingnya SOP bagi mahasiswa magang di The Oberoi Beach Resort, Bali yaitu, kendala yang sering terjadi pada mahasiswa magang yaitu pada proses pemahaman dan penerapan SOP. Banyak dari mahasiswa magang yang belum paham dengan adanya SOP yang sudah ditetapkan. Hal ini terjadi karena kurangnya kesadaran para mahasiswa magang untuk memahami isi dari SOP yang sudah dibuat. Faktor lain yang mengakibatkan hal ini terjadi adalah belum terjalin komunikasi yang baik antara mahasiswa magang dan para senior. Ada beberapa upaya yang dilakukan oleh pihak hotel untuk mengatasi adanya fenomena ini adalah, langkah pertama dengan pemberian materi SOP, baik pengetahuan tentang hotel, prosedur khusus di departemen maupun product knowledge. Setelah dirasa paham tentang hal tersebut, dilanjutkan dengan proses pengamatan di lapangan, dimana para mahasiswa magang mengamati seniornya ketika melakukan standar SOP. Langkah selanjutnya, para mahasiswa magang diberikan kesempatan untuk praktek di lapangan tanpa berinteraksi dengan tamu terlebih dahulu, dengan masih tetap dimonitoring dan dievaluasi oleh seniornya. Jika dianggap telah mampu melewati seluruh tahap di atas baru diberikan kesempatan untuk mengimplementasikan, akan diberikan briefing selama 15 menit sebelum dan sesudah menjalankan operasional sesuai shift dan briefing diberikan langsung oleh para senior dan para senior akan memberikan motivasi kerja kepada para mahasiswa magang agar mereka lebih mudah memahami isi dari SOP. 


\subsection{Saran}

Penelitian ini memiliki beberapa saran yang berkaitan dengan pembahasan diatas, yaitu diharapkan kepada para senior untuk mempermudah pemahaman SOP bagi para mahasiswa magang sebaiknya para senior memberikan pengertian yang lebih sederhana tentang SOP kepada para mahasiswa magang, pihak perusahaan menyadarkan para mahasiswa magang dan karyawan tentang pentingnya SOP yang berlaku agar tetap dijalankan dengan semanamestinya, diperlukan adanya kerjasama dan komunikasi yang baik antara para senior dan mahasiswa magang, diharapkan perusahaan menyadarkan karyawan untuk mengingat tentang complain pelanggan yang pernah terjadi agar menjadi pengalaman di masa depan untuk terhindarnya masalah yang sama, hasil penelitian ini dapat menjadi pedoman atau acuan yang digunakan untuk penelitian selanjutnya yang berkaitan dengan pentingnya pemahaman SOP dan pihak kampus diharapkan dapat menambah wawasan product knowledge seperti pengetahuan tentang jenis kopi dan the bagi para mahasiswa yang akan terjun pada kegiatan PKL pada departemen Food and Beverage Service.

\section{Daftar Pustaka}

Shinta. 2012. Pentingnya Penerapan SOP (Standard Operational Procedures) guna Meningkatkan Pelayanan di Club Olympia Hotel Bumi Surabaya.

Atiyah, Liana. 2018. Implementasi Standar Operasional Procedures Waiter/Waitress dalam Menyajikan Pesanan Tamu di Opi Indah Hotel Palembang. Seminar Hasil HAVOK) Universitas Guna Darma Palembang.

Fedri. 2019. Analisis Kelayakan Inventory Asset Food and Beverage Service terhadap Pengembangan SOP (Standard Operational Procedures) Pelayanan pada Hotel Pusako Bukittinggi. Fakultas Pariwisata Universitas Muhammadiyah Sumatera Barat.

Dadang. 2020. Pengertian Food and Beverage

Arifianto. 2017. Mekanisme Penerapan SOP (Standard Operational Procedures) Waiter di The Travelodge Restaurant, Hotel Santika Premiere Gubeng, Surabaya.

Damanik.2018. Analisis Kemampuan Kerja Pramusaji terhadap Kelancaran Operasional di Food and Beverage Service Department Hotel Losari Blok M2 Jakarta. Jurnal Industri Pariwisata.

Candra, Mohamad Lutfi. 2018. Peran Waiters/Waitress Dalam Meningkatkan Kepuasan Customers Di Restoran Bumbu Desa Aston Hotel and Conference Center. Universitas Jember.

Estrelit. 2016. Pengaruh Penerapan SOP terhadap Kinerja Waiter/Waitressdi Sun Café restoran pada Sun Island Boutique Villas \& Spa Seminyak, Bali. Mahasiswa thesis, Politeknik Negeri Manado. 
JMPP, Vol 3 No 1, April 2020

p-ISSN: 2654-9719

Amirul. 2016. Pentingnya Penerapan Standart Operasional Procedure dalam Pelayanan yang Diberikan oleh Karyawan Terhadap Tamu di Ruby resto Royal Hotel n' Lounge Jember. Universitas Jember.

Wahyuningsih, Silvia. 2018. Penerapan Standard Operating Procedure Pelayanan Waiter Dan Waitress Di Sarkies Restaurant Hotel Majapahit Surabaya. Universitas Jember.

Hardiyanti, Sinta. 2019. Prosedur Kerja Pramusaji Dalam Melayani TAMU DI Javanoa Resto ljen View Hotel \& Resort Bondowoso. Universitas Jember. 